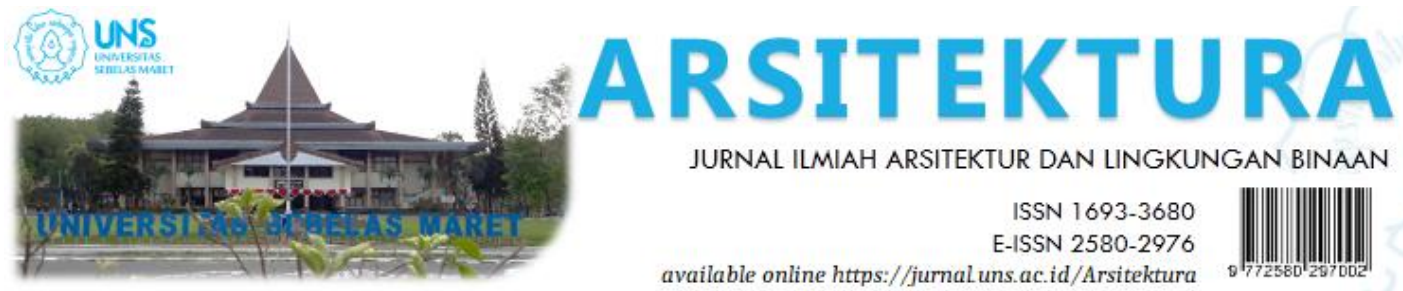

Volume 19 Issue 1 April 2021, pages:25-36

\title{
Strategi Penataan Lahan BUMDes Puntukrejo Ngargoyoso Karanganyar Sebuah Penerapan Konsep Agrowisata
}

\author{
Land Management Strategy of BUMDes \\ Puntukrejo Ngargoyoso Karanganyar \\ an Application of Agritourism Concepts
}

\author{
Musyawaroh $^{1 *}$, T.J. Daryanto ${ }^{2}$, U. Mustaqimah ${ }^{3}$ \\ Study Program of Architecture, Engineering Faculty of Universitas Sebelas Maret ${ }^{1 *}$ \\ ${ }^{*)}$ musyawaroh@staff.uns.ac.id \\ Study Program of Architecture, Engineering Faculty of Universitas Sebelas Maret ${ }^{23}$
}

DOI: https://doi.org/10.20961/arst.v19i1.46104

Received: November 27,2020 Revised: March 28,2021 Accepted: April 5,2021 Available online: April 30,2021

\begin{abstract}
This paper discusses a land management strategy that applies agritourism in BUMDes land in Puntukrejo Village, Karanganyar Regency. An appropriate planning strategy is necessary to manage the village's a gricultural potencies supported by topographic beauty, coolmicroclimate, and various well-known products. This village also has BUMDes relatively wide land assets but is not utilized properly. The agritourism applied in land assets usage is expected to increase rural tourism visits by exposing agricultural activities. The case study method is used in this process because it has suitability, especially in researching a strategy to obtain answers to the question "how" and its argument "why." The analysis process is done descriptively qualitatively. The study identifies community activities and village potencies for determining various tourism activities and resolves land-use allocation. The result is applying agritourism that utilizes the attractiveness of agriculture by displaying the potential of fertility and natural beauty and supporting leading agricultural commodities, facilities, and harmony by equipping supporting facilitiesfor the convenience of visitors supporting infrastructure by providing unique icons.
\end{abstract}

Keywords: Agro-tourism concept, land management, BUMDes assets, Puntukrejo Village

\section{PENDAHULUAN}

Upaya mengembangkan industri wisata di tanah air telah dilaksanakan Pemerintah Indonesia secara masif dalam beberapa tahun terakhir. Hal ini dikarenakan sektor pariwisata merupakan penyumbang devisa terbesar hingga awal tahun
2020. Dalam Rencana Pembangunan Jangka Panjang Nasional tahun 2005-2025 disebutkan bahwa kepariwisataan dikembangkan agar mampu mendorong kegiatan ekonomi dan meningkatkan citra Indonesia, meningkatkan kesejahteraan masyarakat lokal, dan memberikan perluasan kesempatan kerja. 
Pengembangan wisata dengan basis pertanian atau agrowisata memiliki prospek yang sangat menjanjikan, mengingat Indonesia merupakan negara agraris. Agrowisata atau agritourism didefinisikan sebagai beragam praktik yang dikembangkan di area pertanian dengan tujuan untuk menarik kedatangan wisatawan. Agowisata memiliki peran penting dalam usaha meningkatkan pendapatan masyarakat petani, terutama kelompok petani yang tengah mengalami krisis agraria. Strategi peningkatan pendapatan melalui agrowisata memperlihatkan efektifititas saat diterapkan kepada kalangan petani kecil yang sebagian besar tinggal di daerah peri-perkotaan, dan berada di bawah tekanan besar urbanisasi. Agritourism juga memiliki kontribusi bagi keberlanjutan pertanian melalui sajian atraksi pertanian yang mendidik dan memotivasi wisatawan muda tentang pertanian (Rauniyar, Awasthi, Kapoor, \& Mishra, 2020).

Agrowisata juga memiliki potensi menjadi alat pelestarian warisan kebudayaan, khususnya budaya pertanian. FAO menyelenggarakan sebuah program yang mencatat informasi tentang beragam keindahan lanskap yang luar biasa, keanekaragaman hayati pertanian, ekosistem tangguh serta warisan budaya yang berharga di seluruh dunia. Program tersebut adalah Globally Important Agricultural Heritage Systems (GIAHS) yang bertujuan untuk memberikan pengakuan, dukungan dan konservasi sistem warisan pertanian di tingkat global dan nasional serta meningkatkan penghasilan dan menciptakan nilai tambah bagi hasil pertanian sesuai dengan prinsip berkelanjutan. GIAHS tidak hanya berusaha melestarikan sistem warisan pertanian tetapi juga berperan sebagai atlas pertanian dunia, berusaha untuk memperkenalkan situs warisan pertanian yang menakjubkan dan bertindak sebagai alat pemasaran untuk objek agrowisata (Farsani, Ghotbabadi, \& Altafi, 2019).

Desa memiliki peranan penting dalam upaya pembangunan nasional, dikarenakan penduduk Indonesia sebagian besar bermukim di wilayah pedesaan. Hal tersebut memberikan pengaruh yang cukup besar dalam upaya penciptaan stabilitas nasional (Agunggunanto, Arianti, Kushartono, \& Darwanto, 2016). Salah satu cara untuk mendorong pembangunan di tingkat desa adalah dengan diberikan kewenangan oleh pemerintah pusat untuk mengelola secara mandiri lingkup desa melalui lembaga-lembaga ekonomi di tingkat desa.

Lembaga-lembaga tersebut salah satunya adalah Badan Usaha Milik Desa. Desa dapat mendirikan badan usaha milik desa sesuai dengan kebutuhan dan potensi desa. BUMDes diharapkan mampu menstimulasi dan menggerakkan roda perekonomian di pedesaan dan dikelola sepenuhnya oleh masyarakat desa (Pemerintah, 2004). Substansi dan filosofi BUMDes harus dijiwai dengan semangat kebersamaan dan self help sebagai upaya memperkuat aspek ekonomi kelembagaannya.

Kemitraan antar berbagai fihak dalam masyarakat sangat diperlukan guna menjaga keberlanjutan agrowisata. Identifikasi awal dilakukan untuk mengetahui siapa saja yang terlibat dan bagaimana proyek pariwisata pedesaan dijalankan. Ke depannya juga perlu identifikasi tentang peluang membangun jaringan kemitraan baru serta tantangan dalam mempertahankannya. Penting untuk dipertimbangkan juga bahwa masyarakat tidak bersifat homogen, sehingga tidak semua anggotanya ingin bergabung menjadi pelaku pariwisata (Hashimoto \& Telfer, 2010).

Desa Puntukrejo Kecamatan Ngargoyoso Kabupaten Karanganyar memiliki potensi yang sangat tinggi untuk dikembangkan menjadi desa wisata. Desa ini mempunyai lahan BUMDes cukup luas dan belum semuanya termanfaatkan dengan baik. Sudah dilakukan pemanfaatan lahan sebagai lokasi wisata agro, akan tetapi belum optimal. Belum ada penataan yang terencana dan terintegrasi dalam memanfaatkan lahan tersebut. Dibutuhkan master plan rancangan penataan yang agar lahan BUMDes dapat dimanfaatkan dengan baik serta dapat meningkatkan kesejahteraan masyarakat. 


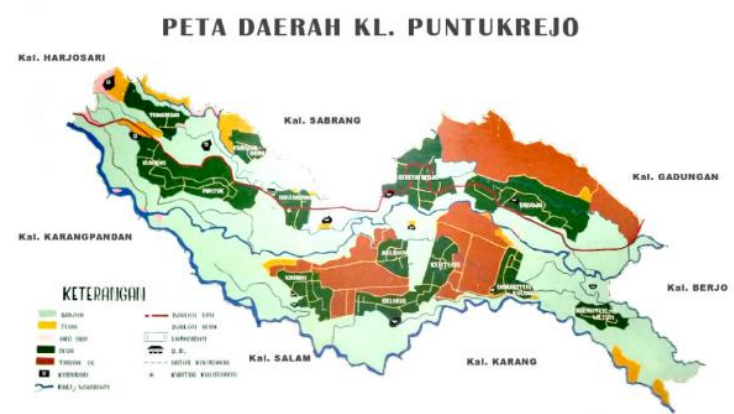

Gambar 1. Peta Desa Puntukrejo Sumber: Desa Puntukrejo.

Permasalahan yang diangkat dalam penelitian ini adalah:

1) Apa saja kegiatan masyarakat dan potensi yang dimiliki oleh Desa Puntukrejo Kecamatan Ngargoyoso Kabupaten Karanganyar.

2) Bagaimana pemanfaatan lahan BUMDes saat ini dan menentukan aktivitas wisata yang layak diterapkan di lahan tersebut.

3) Bagaimana konsep agrowisata yang diterapkan untuk menata lahan BUMDes di Desa Puntukrejo.

\section{METODE}

Metode yang digunakan adalah studi kasus tunggal dengan analisa deskriptif kualitatif (Yin, 2013). Penelitian ini dimulai dengan mengidentifikasi kegiatan masyarakat dan potensi desa yang diperoleh dari observasi lapangan, wawancara dan FGD dengan masyarakat (terdiri dari Pamong Praja, PKK, Tokoh Masyarakat, UMKM dan Pengelola BUMDes). Analisis data dilakukan dengan cara mengevaluasi penggunaan lahan yang telah dilakukan, dan kemudian menentukan kegiatan pariwisata yang tepat untuk diterapkan terintegrasi dengan potensi masyarakat dan kondisi lingkungan yang ada. Konsep agrowisata yang diterapkan untuk menata lahan meliputi Attractions, Facilities, Infrastructure, Transportation dan Hospitality.

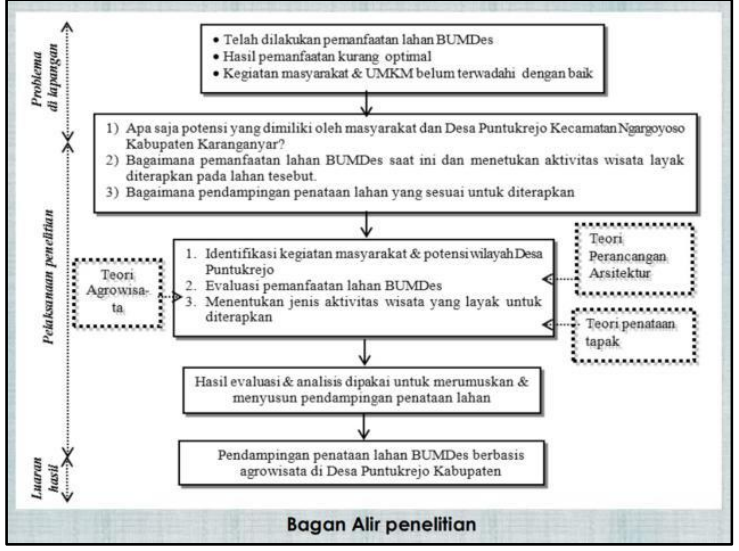

Gambar 2. Bagan Alur Penelitian Sumber: Musyawaroh et al., 2020

\section{HASIL DAN PEMBAHASAN}

Hasil penelitian ini terbagi dalam 2 tahap. Pertama adalah identifikasi potensi masyarakat dan Desa Puntukrejo, serta evaluasi pemanfaatan lahan BUMDes untuk menetapkan ragam aktivitas wisata yang akan dikelola. Ke dua adalah menerapkan konsep agrowisata untuk menata zonasi dan penyelesaian arsitektural wadah pengembangan kegiatan di lahan BUMDes Desa Puntukrejo.

Penggunaan dan jenis kegiatan yang dilakukan masyarakat di lahan BUMDes ada dua macam yaitu kegiatan rutin dan insidentil. Kegiatan rutin yang dilakukan meliputi: 1) penjualan Pecel Pincuk Mbah Puntuk dengan gazebogazebo untuk tempat makan; 2) perparkiran di lahan parkir bagi kendaraan pengunjung Pecel Pincuk Mbah Puntuk, dan pengunjung yang sedang menikmati Tour Wisata Kajepe (Komunitas Jeep Puntukrejo); 3) penanaman bunga (biasanya dilaksanakan pada hari Minggu), beberapa jenis tanaman bunga sudah ditaman di lahan BUMDes; 5) kegiatan bermain, kegiatan outbond, dan tubing mini; 6) kegiatan pertemuan di Rumah Pertemuan Besar (Joglo); serta 7) penjualan oleh-oleh di Kios Oleh-oleh dan Lawu Hik. 


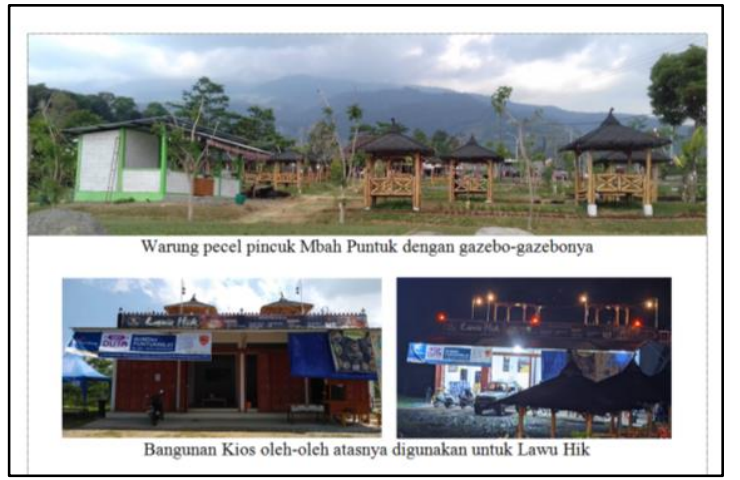

Gambar 3. Wadah Kegiatan Rutin diLahan BUMDes Puntukrejo

Sumber: Musyawaroh et al., 2020

Kegiatan insidentil yang dilakukan warga masyarakat di Puntukrejo meliputi: a) kerja bakti secarab rutin dalam membersihkan dan menata lahan bumdes, yang dilakukan setiap hari Minggu; b) beragam jenis perlombaan dalam rangka memperingati hari kemerdekaan Indonesia setiap tanggal 17 Agustus; c) pentas seni yang melibatkan masyarakat desa dan sekitarnya dilakukan mulai bulan Mei hingga Agustus 2019; dan d) bazar produk UMKM yang dilakukan mulai Mei hingga Agustus 2019.

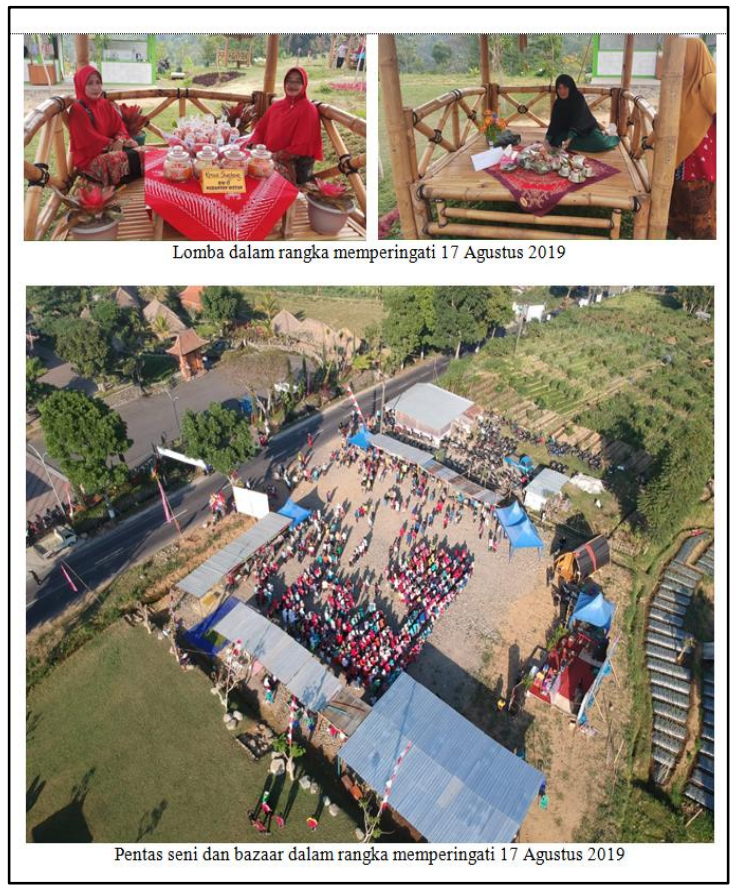

Gambar 4. Kegiatan Insidentil Sumber: (Desa, 2020)

Beraneka ragam produk yang dihasilkan oleh kelompok UMKM yang terdapat di Desa Puntukrejo meliputi produk olahan singkong, ubi rambat, dan ubi ungu; produk karak dan rengginang; aneka macam kripik; kue kering; jamu gendong; serta masakan tradisional. UMKM ini sebagian terdiri dari kelompok ibuibu PKK dan sebagian lagi warga masyarakat. Selama ini pemasaran produk UMKM telah dilakukan melalui beberapa media di antaranya secara online, melalui pameran atau bazaar UMKM, dititipkan pada outlet dan resto yang bekerjasama dengan BUMDes, dan dipasarkan di Kios Oleh-Oleh yang telah dibangun di lahan BUMDes.

Survei memperlihatkan bahwa tanaman komoditas yang cocok ditanam di lahan BUMDes antara lain: strawberry, jambu (Jambu Kristal, Jambu Air dan Jambu Merah), jeruk (Jeruk Dekopon), Anggur Brazil, ketela rambat (Ketela Ungu, Ketela Kuning dan Ubi Cilembu) dan ketela pohon, tanaman bumbu dapur, dan aneka sayur mayur. Namun demikian, tidak menutup kemungkinan untuk dilakukan uji tanaman komoditas baru yang memiliki nilai ekonomi yang lebih tinggi serta berkesuaian dengan kondisi alam di Desa Puntukrejo, Karanganyar.

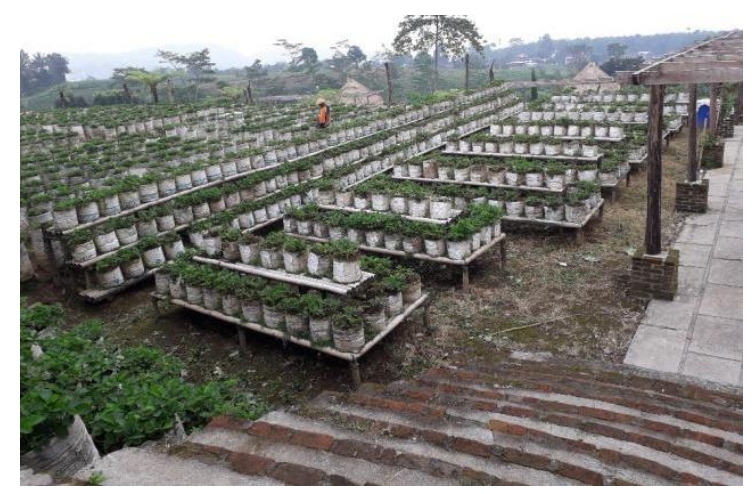

Gambar 5. Kebun Strawberry Puntukrejo (Musyawaroh et al., 2020)

Merespon berbagai aspek di lapangan maka aktivitas wisata yang sesuai diterapkan di lahan BUMDes adalah Wisata Edukasi Pertanian Terpadu. Bentuk wisata di mana pengunjung dapat menikmati wisata khas pedesaan dengan edukasi pertanian beserta segala perlengkapannya. Pengunjung dikenalkan alatalat pertanian tempo dulu, cara menggarap ladang/sawah lengkap dengan sapi dan garunya, cara menanam, cara merawat sapi dan lain-lain. Atraksi tersebut bertujuan untuk memperluas pengetahuan, pengalaman 
rekreasi, dan hubungan usaha di bidang pertanian. Selain menambah pendapatan, kegiatan di atas juga dapat melestarikan sumber daya lahan, serta memelihara budaya maupun teknologi lokal (indigenous knowledge) yang sesuai dengan kondisi lingkungan alaminya.

Potensi Desa Puntukrejo terkait dengan kondisi lingkungan alami dan masyarakatnya dipetakan dalam gambar berikut ini.

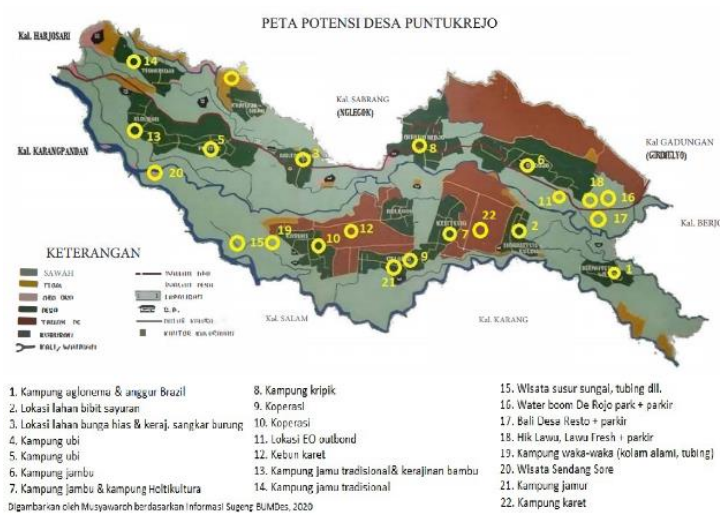

Gambar 6. Peta Potensi Desa Puntukrejo (Musyawaroh et al., 2020)

Salah satu tujuan penataan lahan BUMDes adalah penguatan peranan BUMDes dalam meningkatkan kesejahteraan masyarakat, melalui penguatan kemampuan keuangan desa dalam penyelenggaraan pemerintahan dan peningkatan pendapatan masyarakat melalui berbagai kegiatan usaha ekonomi masyarakat perdesaan (Kementerian Dalam Negeri, 2016).

BUMDes Desa Puntukrejo memiliki lahan seluas $14.125,75 \mathrm{~m} 2$ yang terletak di tepi jalan raya Karangpandan-Ngargoyoso. Lahan ini telah dimanfaatkan sebagai area kuliner warung Pecel Pincuk Mbah Puntuk, gazebo-gazebo dan sarana perlengkapan rekreasi lainnya, akan tetapi pemanfaatan kurang optimal. Data pengukuran dan kondisi lapangan berdasarkan citra satelit google maps adalah sebagai berikut:

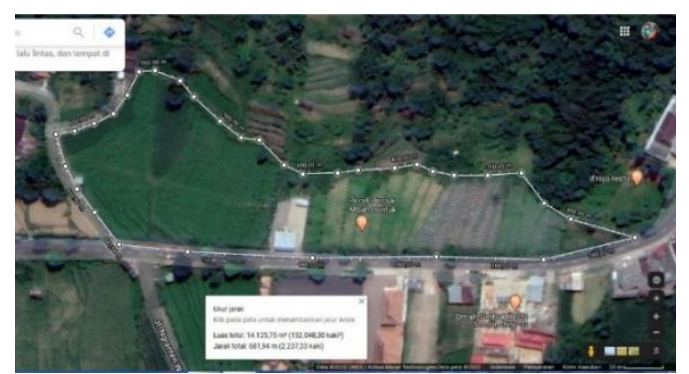

Gambar 7. Foto pengukuran lahan BUMDes (Desa, 2020)
Konsep "Agrowisata" yang akan diterapkan pada lahan BUMDes merupakan pengembangan dari konsep Wisata Edukasi Pertanian Terpadu yang diusulkan oleh masyarakat.

Prinsip-prinsip agrowisata terdiri dari menekankan dampak negatif terhadap alam dan kebudayaan, menyediakan proses pembelajaran tentang pentingnya pelestarian, mengutamakan pemenuhan kebutuhan penduduk lokal dan usaha pelestarian dalam kerjasama bisnis yang diselenggarakan, mengarahkan keuntungan ekonomi untuk pelestarian, tatakelola sumberdaya alam dan kawasan, kejelasan penataan zone pariwisata serta pengelolaannya, mencegah kerusakan daya dukung lingkungan akibat perkembangan pariwisata, serta pemanfaatan sumber energi dengan melindungi lingkungan alam dan budaya.

Agritourism adalah fenomena kompleks yang melibatkan antar hubungan banyak hal, di antaranya karakteristik sosial-ekonomi-budaya masing-masing wilayah, kondisi lanskap dan regulasi pemerintah. Sehingga dalam pengembangan agrowisata terdapat potensi untuk dilakukan penganekaragaman wisata. Keanekaragaman dapat diwujudkan dalam sajian atraksi, fasilitas penduking, infrastruktur, transportasi, serta bentuk keramahtamahan (Nickerson, Black, \& McCool, 2001). Ragam atraksi yang ditampilkan dapat berupa hamparan kebun/lahan pertanian, keindahan alam, keindahan taman, budaya petani tersebut serta segala sesuatu yang berhubungan dengan aktivitas pertanian tersebut. Fasilitas yang disediakan antara lain penambahan sarana umum, seperti telekomunikasi, hotel dan restoran pada sentra-sentra pasar. Infrastruktur yang dimaksud dalam bentuk sistem pengairan, jaringan komunikasi, fasilitas kesehatan, terminal pengangkutan, sumber listrik dan energi, sistem pembuangan kotoran atau pembungan air, jalan raya dan system keamanan. Keramah-tamahan masyarakat akan menjadi cerminan keberhasilan sebuah system pariwisata yang baik.

Agrowisata mendatangkan berbagai keuntungan bagi masyarakat setempat. Adapun keuntungan dari pengembangan agrotourism bagi petani meliputi: meningkatkan perekonomian, konservasi lahan pertanian, 
sarana pendidikan pentingnya pertanian masyarakat, menekan jumlah urbanisasi, meningkatkan daya tarik produk lokal (Barbieri, Sotomayor, \& Aguilar, 2019).

Beberapa faktor penentu yang berperan dalam keberhasilan suatu kegiatan agrowisata: kelangkaan, kealamiahan, keunikan, pelibatan tenaga kerja, optimalisasi penggunaan lahan, keadilan dan pertimbangan pemerataan, serta penataan kawasan (Syamsu, 2001).

Permasalahan pariwisata yang dihadapi Desa Puntukrejo antara lain belum optimalnya pemasaran wisata, serta rendahnya kualitas SDM dan ketrampilan petani, masih rendahnya daya saing dan inovasi produk pertanian dan perkebunan, serta makin berkurangnya tenaga kerja akibat kurangnya minat generasi muda sebagai petani; rendahnya sinergi antar sektor serta belum terintegrasinya perencanaan pembangunan, penganggaran dan monitoring serta evaluasi pembangunan daerah. Kesemuanya mengakibatkan belum optimalnya penanganan kemiskinan.

BUMDes Desa Puntukrejo memiliki 6jenis unit usaha yaitu: parkir, kuliner, agrowisata, koperasi, serta unit EO outbond. Unit parkir berlokasi di lahan BUMDes objek penelitian, sedangkan unit kuliner berupa "Hik Lawu" berlokasi di lahan BUMDes. Unit wisata meliputi Water boom (berlokasi di lahan BUMDes), Wisata alam area Desa Puntukrejo (Alas Karet, Tempuran, Sungai, Persawahan dan lain-lain), serta KJP (Komunitas Jeep Puntukrejo) yang mewadahi jeep-jeep wisata. Unit agrowisata yang ada: "The Lawu Fresh" yang berlokasi di lahan BUMDes, "Bali Berry", berlokasi di seberang lahan BUMDes, serta Kampung bibit.

Penataan lahan BUMDes telah dilakukan bersama masyarakat. Realisasi rencana tata lahan dilakukan secara tambal sulam akibat berbagai kendala, sehingga menghasilkan tata lahan yang kurang terintegrasi secara total.

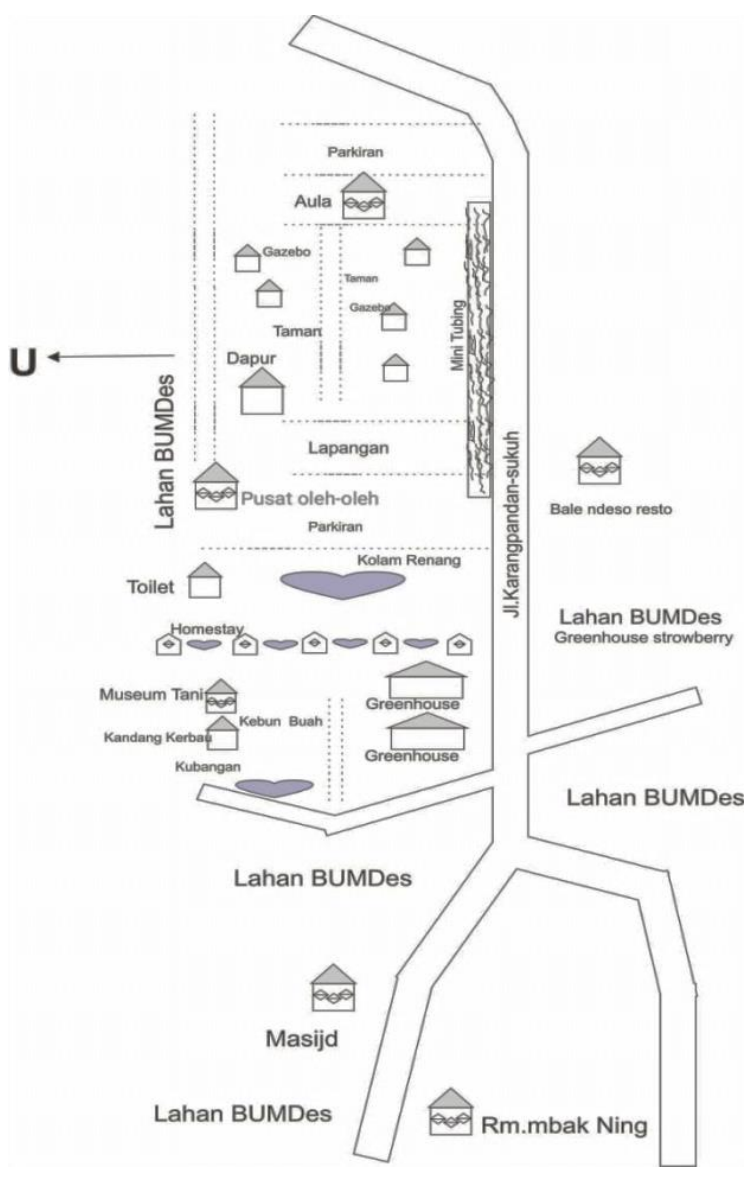

Gambar 8. Zonning Awal Ka wasan (Desa, 2020)

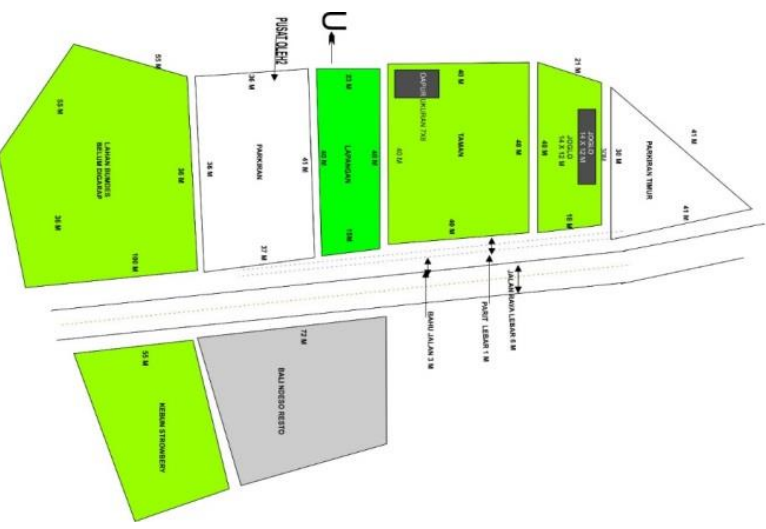

Gambar 9. Da ta pengukuran zonasi pemanfaatan lahan BUMDes Puntukrejo

(Desa, 2020)

Dari zonasi tersebut di atas dan dengan mempertimbangkan hasil FGD serta wawancara dengan warga, tokoh masyarakat, Pamong Praja, UMKM dan PKK, fasilitas yang 
diharapkan akan dibangun di lahan BUMDes adalah sebagai berikut.

a. Pendhopo, sudah dibangun dengan kondisi cukup estetis.

b. Warung pecel Mbah Puntuk, sudah dibangun kondisi kurang estetis.

c. Gazebo, sudah dibangun kondisi cukup estetis.

d. Aula/gedung serba guna untuk kegiatan social kemasyarakatan, rencananya akan dibangun di lokasi yang lain.

e. Kolam renang, akan dibangun di lokasi yang lain.

f. Home stay klasik, rencananya akan dibangun di lahan bagian Barat, tepi jalan.

g. Museum pertanian yang mewadahi alat-alat pertanian tempo dulu, ini yang desainnya akan dirancang di lahan BUMDes

h. Outbond garu dengan kerbau \& kandangnya, kolam pemandian kerbau, ladang sawah untuk garu, akan dibangun di lokasi yang lain.

i. Lapak UMKM, telah dibangun kondisinya cukup estetis. Bagian atasnya untuk "Hik Lawu".

j. Musholla, desainnya akan dirancang di lahan BUMDes.

k. Toilet, desainnya akan dirancang di lahan BUMDes.

1. Ikon Puntukrejo, desainnya akan dirancang di lahan BUMDes

m. Area parkir jeep wisata, lokasinya akan dirancang di lahan BUMDes.

Hasil FGD dan wawancara diintegrasikan dengan hasil observasi lapangan, kemudian dianalisis dengan menerapkan teori agrowisata yang telah dikemukakan dalam kajian teori.

Dari kondisi yang ada, kemudian dilakukan analisis SWOT untuk mengidentifikasi kekuatan dan potensi yang dimiliki oleh lahan dan peluang serta tantangannya di masa yang akan datang. Hasil analisis SWOT dapat dilihat pada tabel berikut ini.
Tabel 1. Ana lisis SWOT

\section{KEKUATAN/POTENSI}

a. Memiliki kemungkinan perkembangan ekonomi tinggi

b. Dikelilingi oleh Resto/Rumah Makan yang besar: "Bali Ndeso", rumah makan "Mbak Ning", rumah makan "Omah Simbok" serta res to cafe "D'rojo".

c. Kebun agro Lawu Fresh

d. Lahan terbuka hijau yang luas

e. Gazebo

f. Pusat oleh-oleh UMKM lokal

g. Lawu Hik

h. KaJePe (komunitas jeep wisata) dikelola oleh dukuh

i. Pemberdayaan masyarakat:

- KaJePe (Komunitas Jeep Puntukrejo), Komunitas Tani Muda Puntukrejo (KTMP), perkumpulan driver Puntukrejo (Diporejo), karang taruna

- Kegiatan pengembangan UMKM oleh ibu-ibu PKK.

j. Agrowisata: sawi, bayam, wortel, tomat, strawberry, golden mama, jeruk, durian, jambu merah, jeruk dekopon, jambu kristal, singkong, ubi, ketela rambat

k. Kegiatan/lahan outbond

1. Kegaitan pentas seni dan bazar UMKM

m. Bangunan joglo/pendhopo

n. Kegiatan kesenian rakyat

o. Potensi kampung-kampung wisata

\section{MASALAH/KELEMAHAN}

a. Kegiatan pengelolaan lahan belum terintegrasi

b. Terbatasnya modal/dana

c. Tempat pemasaran produk UMKM dan pertanian unggulan belum optimal

d. Toilet umum belum memadai

e. Belum ada sentra industri kreatif

f. Pemanfaatan lahan BUMDes belum optimal

g. Belum tersedia tempat penginapan di Puntukrejo

h. Belum tersedia peta potensi wisata untuk penduan pengunjung

i. Belum ada Museum Tani

j. Belum tersedia icon atau penanda bagi BUMDes dan Desa Puntukrejo untuk menarik perhatian wisatawan

$\mathrm{k}$. Belum ada managemen pengelolaan yang terstuktur

1. Belum tersedia pemasaran online

\section{PELUANG}

a. Kerjas ama DPUPR

b. Kerjasama Disperidag

c. Kerjasama Dinas Pertanian

d. Kerjasama Dinas Pariwisata

e. Kerjasama DPU wirausaha mandiri

f. Stakeholder yang terlibat pada bumdes

g. Keterlibatan perguruan tinggi UNS dan UNISRI

h. CSR Jasa Raharja

i. Melibatkan swasta (pemilik Resto/RM/Hotel terdekat)

Pelatihan UMKM 


\begin{tabular}{|l|}
\hline k. APBD Puntukrejo dan donatur lain. \\
1. Dukungan Pemerintah Desa dan Kabupaten. \\
\hline ANCAMAN/TANTANGAN \\
a. Perkembangan potensi wisata di daerah lain \\
dengan objek sejenis \\
b. Perkembangan potensi wisata di sekitar \\
Ngargoyoso \\
c. Kesulitan mengkoordinir antar Dukuh di \\
Puntukrejo
\end{tabular}

Metode penanganan yang dilakukan adalah merespon perkembangan penataan yang telah dilakukan oleh masyarakat. Oleh karenanya, semua masukan bisa diterima dengan terbuka demi perencanaan ke depan yang lebih baik. Hasil penelitian merupakan zonasi awal penataan lahan BUMDes yang siap dikembangkan selanjutnya.

Dalam rancangan penataan ini, BUMDes menjadi starting poin untuk mengenalkan potensi lainnya di Desa Puntukrejo (lihat kembali gambar 6). Prioritas desain mempertimbangkan penguatan ekonomi masyarakat, wisata edukasi pertanian, mengaitkan dengan zonasi yang sudah ada sebelumnya, mensupport kegiatan yang sudah ada, serta mengembangkan agar lebih menarik dan potensial untuk kunjungan wisata.

Fasilitas yang dirancang untuk bisa diwadahi di sisa lahan BUMDes yang tersedia adalah: a) Museum Tani; b) Jembatan penyeberangan orang "JPO Puntuk Agro"; c) Zona Penghubung; dan d) Musholla, Tempat Wudhu dan Toilet; e) Pasar UMKM dan; f) perluasan lahan parkir Barat.

Museum Tani akan mewadahi segala peralatan pertanian tempo dulu seperti cangkul, garu, aniani dan lain-lain. Museum ini langka dan unik serta belum ada wilayah Solo Raya, memberikan pembelajaran pentingnya suatu pelestarian sistem pertanian lokal dimasa lalu kepada generasi muda mengingat Indonesia adalah negara agraris. Konsep ini menyatu dengan konsep agrowisata yang telah diterapkan pada agromart dan lawu fresh. Desain bangunan Museum Tani mengadopsi bentuk pendopo joglo khas Jawa Tengah, yang ditutup dengan dinding kaca untuk melindungi alat-alat pertanian kuno yang disimpan di dalamnya.

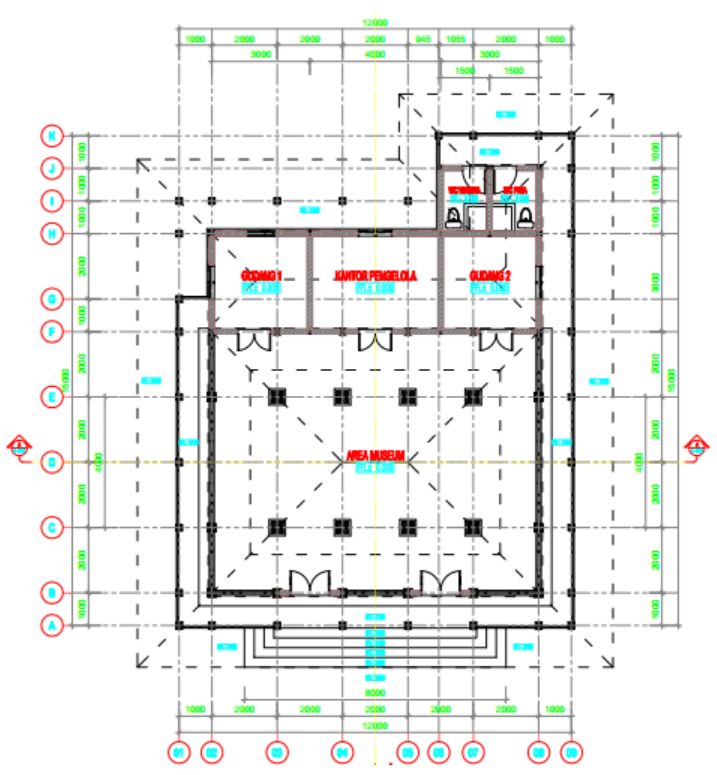

Gambar 10. Denah Museum Tani Musyawaroh et al., 2020

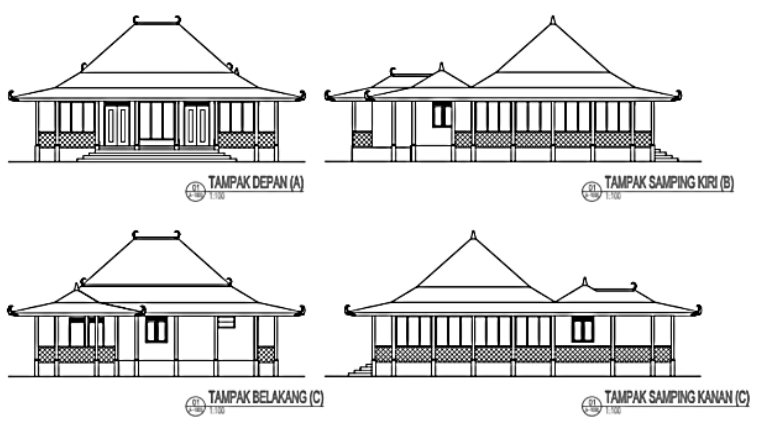

Gambar 11. Tampak Bangunan Museum Tani Musyawaroh et al., 2020

Di sekitar Museum Tani ini diletakkan gazebogazebo yang bisa dimanfaatkan untuk beristirahat bagi pengunjung yang habis mengunjungi Museum atau pengunjung lain yang ingin bersantai di kawasan lahan BUMDes. Bentuk dasar gazebo terinspirasi dari "kandang kebo", yang merupakan bagian dari sistem pertanian kuno. Desain gazebo disajikan dalam gambar berikut ini. 


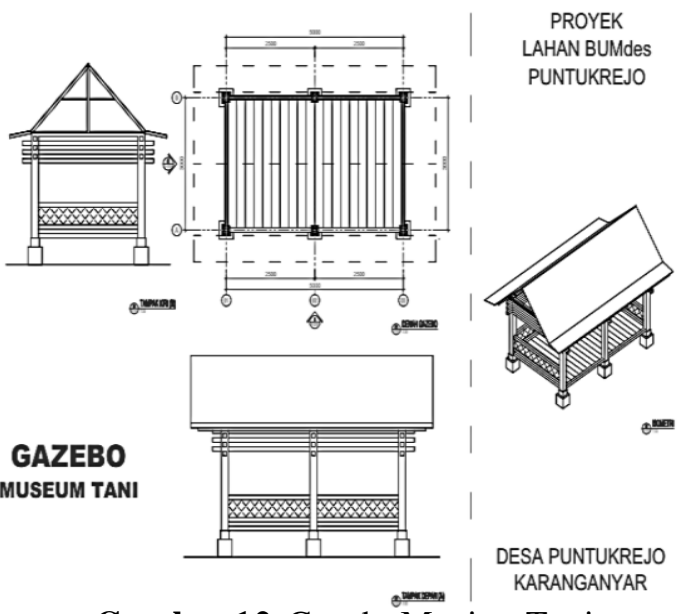

Gambar 12. Ga zebo Musium Tani

Musyawaroh et al., 2020

Jembatan penyeberangan orang "JPO Agro" dirancang untuk menghubungkan area BUMDes dengan Bali Berry melewati atas jalan raya Karangpandan-Ngargoyoso, sekaligus menjadi Icon bagi kawasan agrowisata ini. Hal ini dikarenakan lahan Bali Ndesa Resto dan Bali Berry adalah juga lahan milik BUMDes, yang disewakan pada pihak luar. Suatu saat lahan ini akan kembali kepada pihak BUMDes dan menyatu dengan lahan di seberangnya.

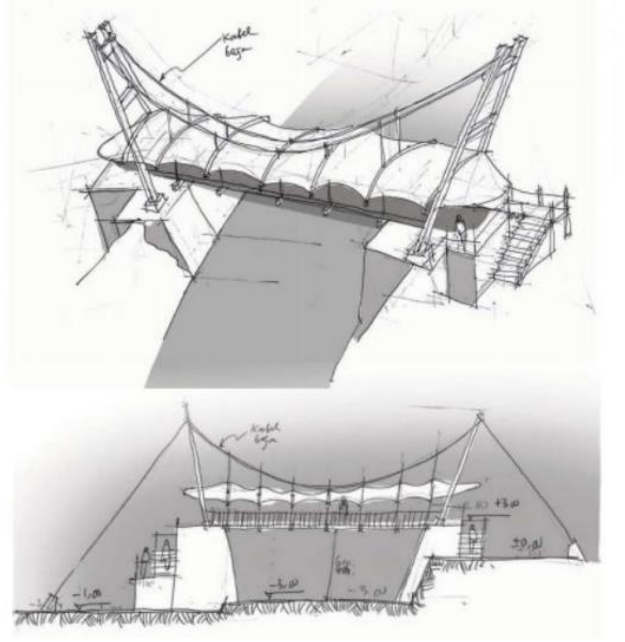

Gambar 13. Jembatan Penyeberangan Orang Musyawarohet al., 2020

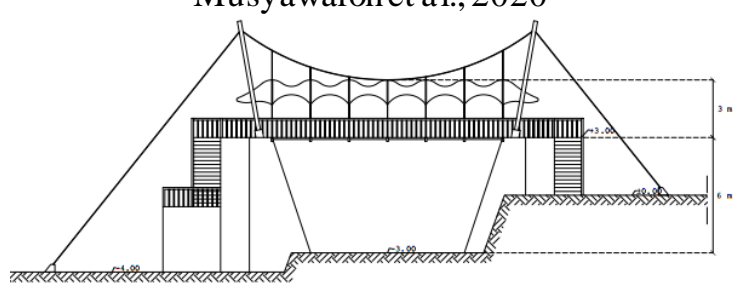

Gambar 14. Tampak Timur JPO

Musyawaroh et al., 2020
Jembatan Penyeberangan Orang (JPO) dirancang sebagai pintu gerbang iconik agar menarik kunjungan wisatawan. Jembatan rangka baja tersebut dilengkapi tanaman rambat untuk menonjolkan citra "kampung agro Puntukrejo". JPO menghubungkan lahan BUMDes dengan kawasan Bali Berry dan Bali Ndesa Resto (lahan BUMDes yang disewakan).

Fasilitas Musholla diletakkan di area yang aksesibel yaitu dekat Pusat Oleh-oleh dan area parkir Barat lengkap dengan tempat wudhu dan toilet.

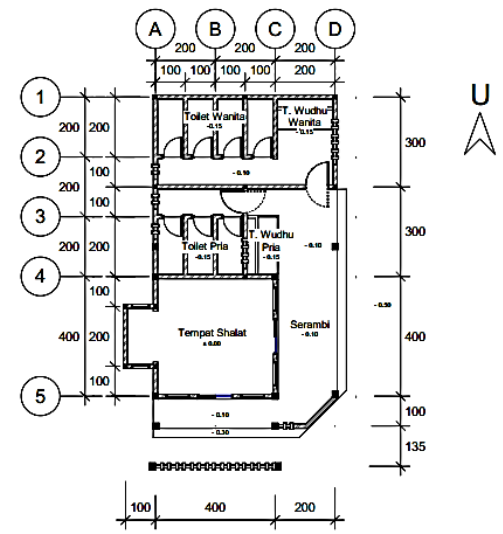

Gambar 15. Denah Musholla

Musyawaroh et al.,2020
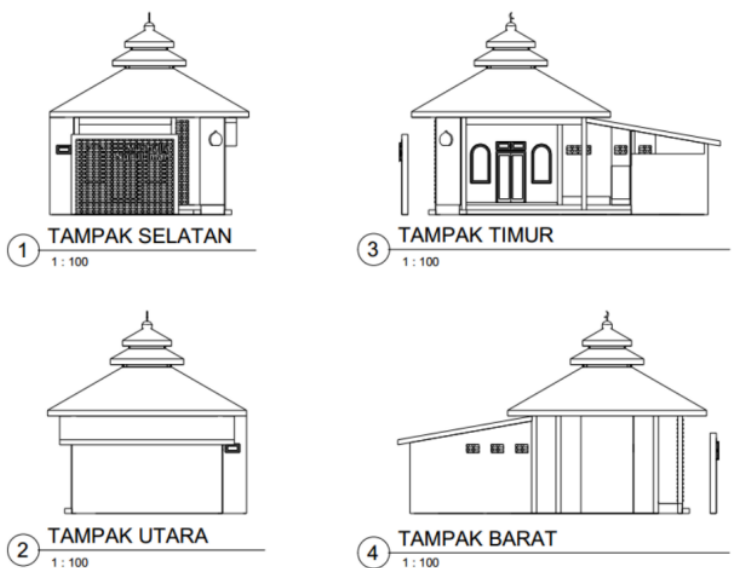

Gambar 16. Tampak Musholla Musyawaroh et al.,2020

Upaya mendorong peningkatan perekonomian, mengurangi arus urbanisasi dan mendukung promosi produk lokal diwujudkan dengan menyediakan Pasar UMKM. Zona Pasar diletakkan di area sebelah utara dengan lahan paling luar di area ini.

Zonasi atau mintakat keseluruhan lahan BUMDes Desa Puntukrejo diperlihatkan pada gambar berikut. 


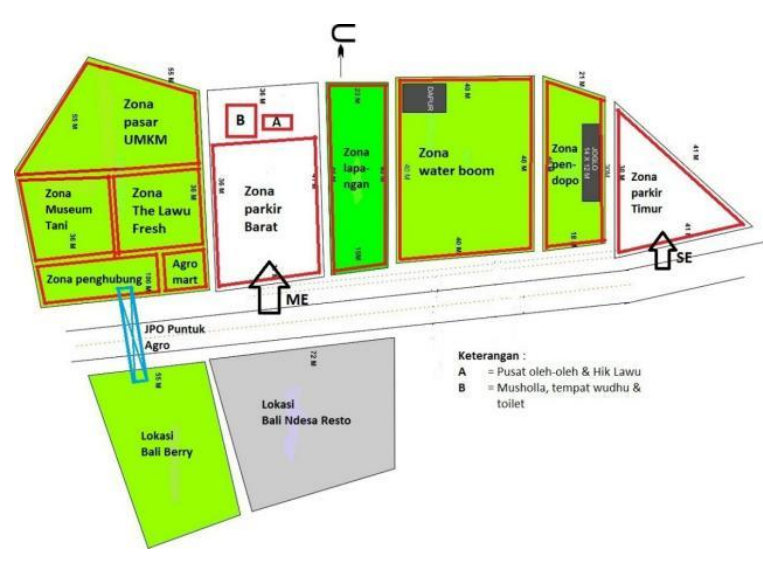

Gambar 17.Zonning Penataan AwalLahan BUMDes

Musy awarohet a1., 2020

Hasil zonasi didiskusikan dengan masyarakat dan pengelola BUMDes untuk memperoleh masukan masukan. Pelibatan masyarakat bertujuan agar hasil perencanaan dan perancangan bisa tepat guna dan sesuai dengan aspirasi masyarakat. Masyarakat masyarakat dijadikan subjek dari upaya pembangunan, dilibatkan secara aktif dan sukarela dalam keseluruhan proses kegiatan agar mampu menolong dirinya sendiri.

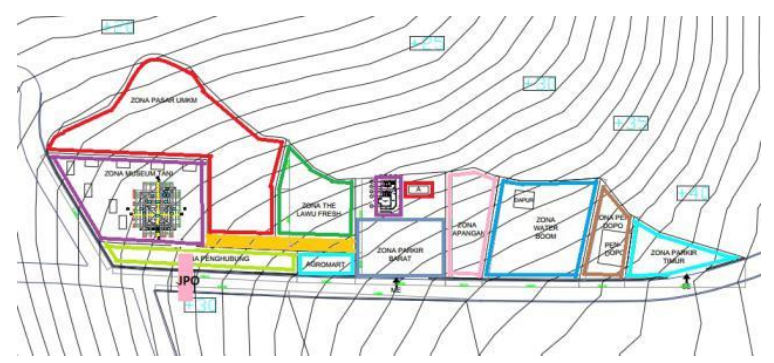

Gambar 18. Penerapan Zonning Penataan a wal pada Lahan BUMDes

Musy awaroh et a 1., 2020

Upaya tata ulang lahan dimaksudkan agar terjalin dukungan antar kegiatan secara berkelanjutan.

1. Zona Parkir Timur. Zona parkir digunakan untuk area parkir jeep KaJePe dan pengunjung dari arah Ngargoyoso.

2. Zona Pendopo. Zona pendopo digunakan untuk tempat berkumpul pengunjung dalam jumlah besar (telah mendaftar terlebih dahulu), dan tempat melaksanakan event-event khusus indoor.
3. Zona Water Boom, digunakan untuk sarana rekreasi air bagi keluarga dan menunjang kegiatan lain di kawasan wisata agro ini.

4. Zona Lapangan, untuk pelaksanaan eventevent tertentu, sehari-hari dimanfaatkan untuk ruang terbuka untuk space pengikat antar kegiatan dan space penerima dari zona Parkir Barat.

5. Zona Parkir Barat, digunakan untuk parkir kendaraan pengunjung yang berasal dari arah Solo-Karangpandan. Pintu masuk utama (main entrance) berada di zona ini.

6. Pusat Oleh-Oleh \& Hik Lawu. Pusat Oleholeh mewadahi kegiatan pemasaran hasil karya UMKM Puntukrejo. Bangunan ini diletakkan dekat parkir Barat untuk mempermudah akses pengunjung. Bagian atas bangunan ini dimanfaatkan untuk Hik Lawu pada malam hari.

7. Agromart, diletakkan di dekat jalan raya, agar lebih terekspos dan untuk mempermudah akses dari pembeli.

8. Zona The Lawu Fresh, diletakkan ditengahtengah zonasi kegiatan bagian barat, berfungsi sebagai open space dan taman pengikat antar zona.

Lahan BUMDes dirancang menjadi starting point bagi seluruh kegiatan "Desa Wisata Puntukrejo" yang memiliki berbagai macam potensi unggulan, transportasi ke Dukuh unggulan menggunakan jeep wisata "KaJePe" yang dikelola oleh masing-masing Dukuh di Desa Puntukrejo. Penyediaan sarana transportasi ini menerapkan konsep transportation dari agrowisata

Selanjutnya, dilakukan diseminasi hasil penelitian kepada masyarakat Desa Puntukrejo. Dari kegiatan diseminasi tersebut diperoleh banyak masukan yang dapat dipergunakan untuk menyempurnakan zonning penataan awal. 


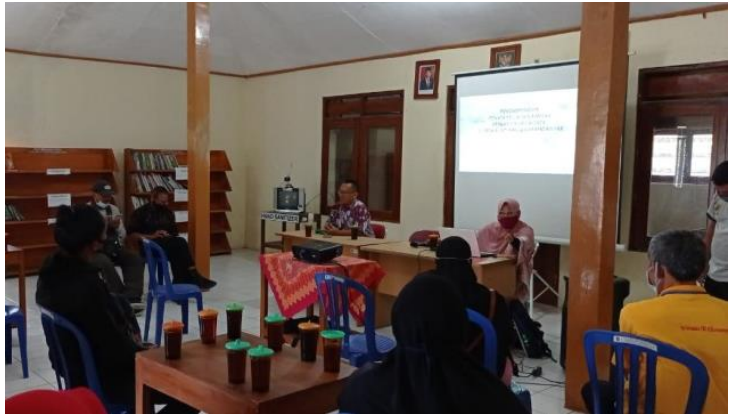

Gambar 19. Diseminasi hasil penelitian Dokumentasi : Mustaqimah, 2020

Dari diseminasi tersebut diperoleh beberapa masukan untuk desain dan zonning.

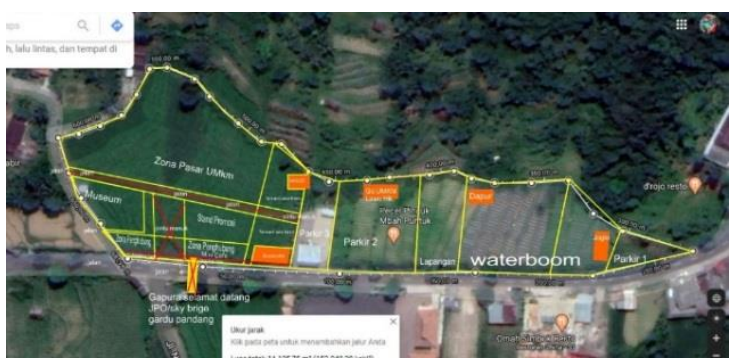

Gambar 20. Masukan untuk Zonning (Desa, 2020)

Masyarakat menghendaki akses di lahan bagian Barat tetap dipertahankan di tengah, seperti eksisting yang ada. Lahan parkir diperluas, karena pada saat akhir pekan atau liburan, lahan parkir sudah tidak dapat mewadahi kendaraan pengunjung. Area ini juga akan diberi perkerasan. Perlu memberikan pintu masuk di area dekat JPO. Zona The Lawu Fresh boleh digeser. Dari hasil masukan tersebut, zonning penataan awal kemudian disempurnakan.

Respon terhadap rancangan penataan akhir terhadap masukan dari masyarakat adalah sebagai berikut:

Pertama, akses jalan setapak di tengah bisa dipertahankan, akan tetapi tidah menembus sampai ke ujung lahan. Akses ini berhenti di tepi zona Parkir Barat perluasan.

Kedua, diberikan tambahan zona perluasan parkir Barat, untuk menampung kendaraan pengunjung saat hari-hari padat. Area ini multi fungsi, bisa dipakai untuk mewadahi eventevent tertentu bila diperlukan. Jenis perkerasan yang paling sesuai dan ramah lingkungan menggunakan grass block, agar air tetap bisa meresap masuk ke dalam tanah.
Ketiga, pintu masuk harus tetap diletakkan pada tepi-tepi area parkir, agar fokus pengunjung yang akan masuk ke lahan BUMDes tidak terpecah. Area ini bisa diberi gapura yang menarik agar lebih terekspos.

Proses perencanaan dan perancangan yang melibatkan pengelola BUMDes dan masyarakat Puntukrejo berlangsung dengan baik, dari awal hingga akhir. Perencanaan akhir penzonningan lahan bisa dilihat dari gambar berikut ini. Mengakomodasi semua masukan tersebut, kemudian disusun zonning penataan akhir sebagai berikut.

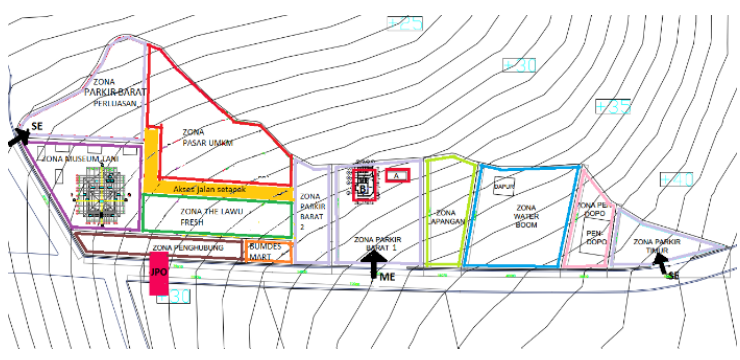

Gambar 21.Zonning Penataan AkhirLahan BUMDes

Musyawaroh et al.,2020

Penataan ini diharapkan dapat mewadahi semua aspirasi pengembangan yang telah diusulkan oleh masyarakat, dan dapat dijadikan acuan untuk pengembangan pada tahap-tahap selanjutnya.

\section{KESIMPILAN}

Desa Puntukrejo adalah salah satu desa di Kecamatan Ngargoyoso Kabupaten Karanganyar yang memiliki potensi yang sangat besar untuk dikembangkan menjadi Desa Wisata. Desa ini memiliki lahan BUMDes relatif luas di tepi jalan raya yang telah dimanfaatkan untuk meningkatkan perekonomian masyarakat akan tetapi belum optimal.

Konsep agrowisata diterapkan untuk menata lahan BUMDes tersebut, dengan tujuan mewadahi kegiatan wisata edukasi pertanian terpadu dan seluruh potensi unggulan yang dimiliki oleh desa.

Konsep agrowisata yang diterapkan untuk menata lahan meliputi attractions, facilities, infrastructure, transportation dan hospitality. Aplikasinya adalah pada perencanaan 
penzonningan pada lahan, dilengkapi dengan desain bangunan pendukungnya yakni museum tani, JPO, zona penghubung, musholla, pasar UMKM serta perluasan lahan parkir.

Perencanaan dan perancangan ini diharapkan mampu memberi solusi, dan membuka peluang untuk pengembangan selanjutnya.

\section{UCAPAN TERIMAKASIH}

Ucapan terima kasih dipersembahkan kepada pihak-pihak yang membantu penelitian ini :

1. Masyarakat dan Pamong Praja Desa Punturejo, atas segala informasi dan dukungan yang diberikan.

2. LPPM UNS, yang memberikan kesempatan dan dukungan finansial.

3. Pemerintah Daerah Kabupaten Karanganyar dan segenap jajarannya, atas kesempatan dan dukungan data yang diberikan.

4. Prodi Arsitektur UNS, atas kesempatan dan dukungan peralatan yang diberikan.

\section{REFERENSI}

Agunggunanto, E., Arianti, F., Kushartono, E., \& Darwanto. (2016). Pengembangan Desa Mandiri melalui Pengelolaan Badan Usaha Milik Desa ( Bumdes ). JDEB, 13(1), 67-81.

Barbieri, C., Sotomayor, S., \& Aguilar, F. X. (2019). Perceived Benefits of Agricultural Lands Offering Agritourism. Tourism Planning and Development, 16(1), 43-60. https://doi.org/10.1080/21568316.2017.1 398780

Desa, P. D. P. (2020). Potensi Desa Puntukrejo. Karanganyar.

Farsani, N. T., Ghotbabadi, S. S., \& Altafi, M. (2019). Agricultural heritage as a creative tourism attraction. Asia Pacific Journal of Tourism Research, 24(6), 541-549. https://doi.org/10.1080/10941665.2019.1 593205

Hashimoto, A., \& Telfer, D. J. (2010). Developing sustainable partnerships in rural tourism: The case of oita, japan. Journal of Policy Research in Tourism, Leisure and Events, 2(2), 165-183. https://doi.org/10.1080/19407963.2010.4 82276

Kementerian Dalam Negeri. Peraturan Menteri Dalam Negeri Republik Indonesia (2016).
Musyawaroh, Daryanto, T. J., Marlina, A., Cahyono, U. J., Mustaqimah, U., Pramesthi, L., ... Swastika, M. (2020). Pendampingan Penataan Lahan Bumdes Berbasis Agrowisata Di Desa Puntukrejo Karanganyar, Penelitian Hibah Grup Riset, LPPM Universitas Sebelas Maret. Surakarta.

Nickerson, N. P., Black, R. J., \& McCool, S. F. (2001). Agritourism: Motivations behind farm/ranch business diversification. Journal of Travel Research, 40(1), 19-26. https://doi.org/10.1177/00472875010400 0104

Pemerintah, I. Undang-Undang No 32 Tahun 2004 Tentang Pemerintah Daerah, Dpr $\S$ (2004). Retrieved from http://www.dpr.go.id/dokjdih/document/ uu/33.pdf

Rauniyar, S., Awasthi, M. K., Kapoor, S., \& Mishra, A. K. (2020). Agritourism: structured literature review and bibliometric analysis. Tourism Recreation Research, $\quad O(0), \quad 1-19$. https://doi.org/10.1080/02508281.2020.1 753913

Syamsu, Y. (2001). Penerapan Etika Perencanaan pada Kawasan Wisata, Studi Kasus di Kawasan Agrowisata Salak Pondoh, Kabupaten Sleman, Daerah Istimewa Yogyakarta. Journal Ilmiah LP3M STP Trisakti, 5 (3 Maret).

Yin, R. K., 2013. Studi Kasus : Desain dan Metode. Terjemahan Case Study Research : Design and Methods. Jakarta: Raja Grafindo Persada. 